\title{
$\mathrm{AHP}$ 방법을 적용한 국립검역소 평가 준거의 가중치 결정
}

정문용 ${ }^{1}$, 이무식 ${ }^{2 *}$, 김대경 ${ }^{3}$, 유인숙 ${ }^{4}$

${ }^{1}$ 건양대학교 보건복지대학원 보건학과, ${ }^{2}$ 건양대학교 의과대학 예방의학교실,

${ }^{3}$ 목원대학교 스포츠산업과학부, ${ }^{4}$ 건양대학교 일반대학원 보건학과

\section{Determining Relative Weights of Criteria for Evaluating National Quarantine Station by the Analytic Hierarchy Process}

\author{
Mun-Yong Jeong ${ }^{1}$, Moo-Sik Lee ${ }^{2 *}$, Dae-Kyung Kim ${ }^{3}$ and In-Sook Yoo \\ ${ }^{1}$ Department of Public Health and Welfare Graduate school of Konyang University, \\ ${ }^{2}$ Department of Preventive Medicine, College of Medicine, Konyang University, \\ ${ }^{3}$ Department of Sports Industry Science of Mokwon University, \\ ${ }^{4}$ Department of Public Health, The Graduate School of Konyang University
}

\begin{abstract}
요 약 신종 및 재출현 전염병이 지속적으로 유행하고 해외 전염병의 국내유입 가능성이 증대됨에 따라 국립검역소 의 검역관리 사업의 효율성 평가는 매우 중요하다. 본 연구는 평가 구성요소 사이의 상대적 중요도, 즉 가중치 (weight) 부여에 있어서 과학적 타당성을 인정받고 있는 계층분석절차(Analytical Hierarchy Process; AHP) 기법에 의 한 이원비교방법을 사용하여 설정하였다. AHP기법은 복잡한 다기준 의사결정문제(multi-criteria decision making problem)를 계층화하여 단순화체계화시킴으로써 그 영향도를 계량화하는데 탁월한 기법이라는 평가를 받고 있다. 평 가지표별 가중치는 기관평가 영역이 0.2 , 서비스 및 프로그램 영역이 0.8 로 분석되었으며, 서비스 및 프로그램 영역 내에서 검역 업무가 0.45 로 가장 높게 나타났다. 대영역(기관평가영역, 서비스 및 프로그램평가 영역), 중영역(투입, 과정, 결과, 검역업무, 검사업무, 위생관리업무, 병원체조사감시업무, 전염병예방홍보·교육업무)으로 구분하여 최종적으 로 평가지표로 선정된 지표는 실제 국립검역소 사업에 적용하였으며, 이에 대한 최소한의 평가지표를 최종 선정하여 향후 국립검역소 사업평가 체계를 보다 체계화 하였다.
\end{abstract}

\begin{abstract}
In accordance with the increasing possibility that the new and reoccurring epidemics continuously appearing abroad flow into Korea, it is very important to evaluate the efficiency of quarantine management projects of National Quarantine Station. This study adopted the pairwise comparison approach using the analytical hierarchy process(AHP) that has been recognized with its scientific adequacy for allocating the weight, the relative importance of evaluation components. AHP technique is evaluated to be distinguished in measuring the impact by making hierarchy of, simplifying and systemizing the complicated multi-criteria decision making problems. The weights by evaluation indexes were 0.2 in the organization evaluation field and 0.8 in the service and program field. The quarantine business showed the highest value, 0.45 , in the service and program field. The indexes were classified into the upper category (organization evaluation field, service and program evaluation field) and lower category (input/process/result/quarantine field, inspection field, hygiene management field, pathogenic organ investigation and monitoring field, epidemics prevention promotion/education field). The evaluation indexes that were finally selected were applied to the actual businesses in National Quarantine Station. Next, the minimum evaluation indexes were selected and so the evaluation system on the businesses in National Quarantine Station was more systemized.
\end{abstract}

Key Words : AHP(Analytic Hierarchy Process)

\footnotetext{
"교신저자 : 이무식(mslee@konyang.ac.kr) 


\section{1. 서론}

1980년대 이후 사회·경제적인 발전과 더불어 급성 전염병의 발생도 급격히 감소하여 사회적으로 전염병에 대한 심각성이 저하되었다. 그러나 1990년 접어들면서 지구온난화와 더불어 신종 및 재출현 전염병이 급증하고 있다.

우리나라를 포함하여 전 세계적으로 국가 간 교역과 여행의 증가로 해외 유입 질환과 2000년 이후 사스 (SARS)와 조류 인플루엔자 등 국제적인 수준의 전염병 발생이 우려되면서 다시 전염병 관리에 대한 중요성이 부각되기에 이르렀다. 지금까지의 검역관리 사업 평가는 부분적으로 모니터링, 평가되었고, 평가의 틀 개발 및 평 가지표는 국립검역소의 특수성을 고려하여 개발되지 못 했다[1]. 이에 따라 각 국립검역소의 검역관리 사업을 정 량적으로 평가하고, 평가지표를 개발-적용하여 우수기 관을 발굴, 확산하고 새로운 환경 변함으로써 국가 검역 관리 체계 강화를 도모하는 것이 반드시 필요한 상황이 라 할 수 있다. 우리나라 질병관리 본부에서는 효율적인 전염병관리 체계를 구축하기 위하여 전염병 관리 사업에 대한 평가를 꾸준히 시행해 왔으며 기존의 이러한 평가 사업 평가 틀의 개발과 평가지표 개발 연구와 더불어, 지 속적인 연구가 수행되어야 하고, 평가수행체계 개선도 필 요한 실정이다. 따라서 본 연구는 국립검역소의 사업평가 틀을 개발하고, 평가지표를 개발 및 모의 평가를 실시 적용함을 목적으로 한다.

보건복지부와 그 소속기관 직제의 검역지원팀 사무에 국립검역소 심사평가 업무가 분장되어 있으나, 2007년 4 월 현재까지 평가체계 및 평가지표의 개발 등이 준비되 지 못한 실정이다. 검역소 평가를 위해서 전국 13 개 국립 검역소가 공감할 수 있는 객관적인 평가기준 개발이 전 제되어야 하므로 객관적으로 신뢰할 수 있는 평가지표를 개발하고, IHR((International Health Regulation)에서 제시 한 검역소 핵심역량 강화방안 등을 제시하여야 하며, 국 가 검역관리 사업의 정도관리 및 평가체계 구축을 통해 국제적인 전염병관리 사업의 역량을 강화하고 향후 발전 방향을 모색하고자 한다.

\section{2. 연구대상 및 방법}

\section{1 연구방법}

선정된 최종 평가지표는 $\mathrm{AHP}$ 분석 기법을 활용하여 가중치를 결정하였다. 각 세부 평가 기준에 대한 쌍대비
교는 9점 척도[2]를 이용하여 평가하였으며, 개별 구성원 들의 평가자료를 종합하는 방법으로는 기하평균법을 이 용하였다. 설문지 분석을 위한 AHP기법에 의한 통계분 석을 위해서 Expert choice 회사가 만든 전문프로그램인 Expert choice 2000 프로그램을 사용하였다.

\section{2 연구대상}

전염병 관리사업의 평가항목의 가중치 선정을 위하여 관련 분야의 전문가 및 전염병 관리업무를 당하고 있는 지방 공무원을 중심으로, 연구 대상을 선정하였다. AHP 방법에 의한 설문은 전문지식을 가지고 있는 대상자들에 게 실시하는 것으로, 많은 수를 대상으로 하기보다는 전 문성 있는 집단을 대상으로 실시하는 것이 효과적이므로, 본 연구에서는 전국의 검역소장 8 명, 관련 학계의 연구원 및 학자 7 명 등 총 15 인을 대상으로 하였다.

전문가 집단을 대상으로 한 설문 이전에 도출한 1 차 평가항목 및 기준을 전문가 집단에 제시하고, 이에 대한 의견조사 및 평가를 거쳐 최종 평가항목 및 기준, 평가계 층을 설정하였다.

\section{3 분석 방법론 및 적용}

$\mathrm{AHP}$ 를 통한 의사결정은 일반적으로 다음의 6단계를 거치게 되는데, 각 단계를 본 연구에 적용하여 설명하면 아래와 같다.

(1) 단계 1: 목표의 설정 및 의사결정요소의 도출

(2) 단계 2: 의사결정모델의 설정

(3) 단계 3: 쌍대비교를 통한 요소들의 평가

(4) 단계 4: 논리적 일관성의 검증

(5) 단계 5: 통합 및 그룹 평가결과 도출

(6) 단계 6: 민간도분석 및 피드백

\section{3. 결과}

\section{1 평가지료 개발 및 적용을 위한 평가 틀}

국립검역소 기관평가는 투입(기관역량), 과정 및 결과 영역으로 평가되고 있으며, 다양한 검역서비스 및 프로그 램 평가 틀을 검토하여 이에 대한 적절한 평가지표를 개 발하고 적용하였다.

이를 위해 토론, 검역현장 방문조사, 워크샵, 설문조사, 회의 및 $\mathrm{AHP}$ 기법에 의한 지표영역, 세부지표 가중치 및 일관성을 고려하여 최종지표를 개발하였다. 대영역(투입, 과정, 결과) 및 중영역으로 구분하여 최종적으로 평가지 표로 선정된 지표는 실제 국립검역소 사업에 적용하였다. 
국립검역소의 평가는 기관평가와 서비스 및 프로그램 영 역으로 크게 구분하여 지표를 검토하였다. 기관 평가부문 에 대하여 평가영역별로 각기 평가지표를 제안 검토하고, 서비스 및 프로그램 부문에서도 각 평가영역별로 세부적 으로 지표를 제안, 검토하였다. 서비스 및 프로그램 부문 은 국립검역소의 주요 업무부문 5 가지 이상으로 재분류 하였다.

\section{2 평가지표 개발 기준}

평가지표의 개발기준은 자료수집 가능성, 타당성 또는 정확성, 유용성 3 가지로 하였다.

(1) 자료수집 가능성

(2) 타당성(Validity) 또는 정확성(Accuracy)

(3) 유용성(Availability)

\subsection{AHP 기법을 이용한 가중치 설정모형}

국립검역소사업의 평가를 위하여 기관평가 영역과 서 비스 및 프로그램평가 영역으로 구성하였으며, 기관평가 영역은 투입, 과정, 결과로 구성하였다. 서비스 및 프로그 램 영역은 검역업무, 검사업무, 위생관리업무, 병원체조 사감시업무, 전염병 예방홍보·교육 업무 등으로 구성하 였다(표1).

[표 1] AHP를 위한 평가영역 및 평가지표 수

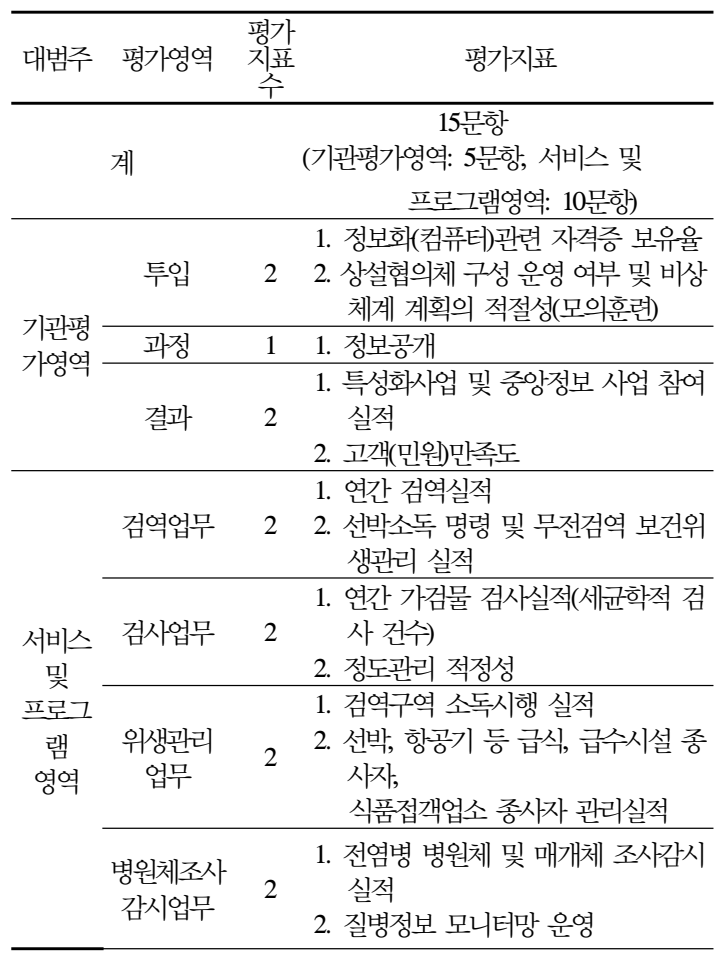

\begin{tabular}{ccc}
\hline $\begin{array}{c}\text { 예방교육 } \\
\text { 및 }\end{array}$ & $\begin{array}{c}\text { 1. 전염병 예방을 위한 지역 언론홍보 } \\
\text { 실적 및 } \\
\text { 홍보 업무 }\end{array}$ & $\begin{array}{l}\text { 유관기관 및 단체 교육 실적 } \\
\text { 2. 전염병 예방접종 실적 }\end{array}$ \\
\hline
\end{tabular}

\section{4 평가범주별 가중치 부여 결과}

의사결정 참여자 모두의 대범주 평가영역 간 쌍대비교 를 통합한 결과, ‘서비스 및 프로그램 영역'이 ‘기관평가 영역'에 비해서 4 배 정도 더 중요한 것으로 나타났다(표 2).

[표 2] 대범주 평가영역의 가중치

\begin{tabular}{ccc}
\hline 평가영역 & $\begin{array}{c}\text { 서비스 및 } \\
\text { 프로그램 영역 }\end{array}$ & 기관평가 영역 \\
\hline 가중치 & 0.796 & 0.204 \\
\hline
\end{tabular}

중범주 평가항목의 가중치 부여 결과 기관평가 영역에 서는 '결과', '투입', '과정'의 순으로 중요한 것으로 나타 났으며, 가중치는 각각 $0.488,0.320,2$ 0.192로 나타났다(표3).

[표 3] 중범주 영역-기관평가영역의 가중치

\begin{tabular}{cccc}
\hline 평가영역 & 결과 & 투입 & 과정 \\
\hline 가중치 & 0.488 & 0.320 & 0.192 \\
\hline
\end{tabular}

\section{5 국립검역소 평가지표 가중치 부여 결과}

$\mathrm{AHP}$ 분석 결과 국립검역소 평가지표별 가중치는 '연 간 검역실적', ‘연간 가검물 검사 실적', ‘선박소독 명령 실적 및 무전검역 보건위생관리', ‘고객(민원)만족도'의 순으로 도출되었다(표4).

[표 4] 국립검역소 최종 평가지표의 가중치 분석결과

\begin{tabular}{|c|c|c|c|}
\hline 평가지표 & 통 합 & 학 계 & $\begin{array}{c}\text { 질병관리본 } \\
\text { 부 } \\
\text { 및 } \\
\text { 국립검역소 }\end{array}$ \\
\hline 연간 검역실적 & 0.352 & 0.331 & 0.346 \\
\hline 연간 가검물 검사실적 & 0.111 & 0.066 & 0.188 \\
\hline $\begin{array}{l}\text { 선박소독 명령 실적 / } \\
\text { 무전검역 보건위생관리 }\end{array}$ & 0.097 & 0.089 & 0.104 \\
\hline 고객(민원) 만족도 & 0.062 & 0.079 & 0.032 \\
\hline $\begin{array}{l}\text { 상설협의체 구성 운영 여부 } \\
\text { 및 비상체계 계획의 } \\
\text { 적절성(모의훈련) }\end{array}$ & 0.053 & 0.051 & 0.054 \\
\hline 전염병 예방을 위한 지역 & 0.050 & 0.062 & 0.036 \\
\hline
\end{tabular}


언론홍보 실적 및

유관기관 및 단체 교육 실적

\begin{tabular}{|c|c|c|c|}
\hline $\begin{array}{l}\text { 전염병 병원체 및 매개체 } \\
\text { 조사감시 실적 }\end{array}$ & 0.049 & 0.043 & 0.059 \\
\hline 검역구역 소독시행 실적 & 0.042 & 0.039 & 0.041 \\
\hline 정보 공개 & 0.039 & 0.051 & 0.026 \\
\hline $\begin{array}{l}\text { 특성화사업 및 중앙정부 } \\
\text { 사업 참여 실적 }\end{array}$ & 0.038 & 0.080 & 0.012 \\
\hline 정도관리 적정성 & 0.034 & 0.030 & 0.038 \\
\hline $\begin{array}{l}\text { 선박,항공기 등 급식, } \\
\text { 급식시설 종사자, 식품 } \\
\text { 접객업소 종사자 관리 실적 }\end{array}$ & 0.034 & 0.031 & 0.033 \\
\hline $\begin{array}{l}\text { 질병정보 모니터망 운영 } \\
\text { 실적 }\end{array}$ & 0.016 & 0.021 & 0.013 \\
\hline $\begin{array}{l}\text { 정보화(컴퓨터)관련 자격증 } \\
\text { 보유율 }\end{array}$ & 0.012 & 0.013 & 0.010 \\
\hline 전염병 예방접종 실적 & 0.010 & 0.013 & 0.008 \\
\hline
\end{tabular}

\section{4. 고찰}

본 연구는 먼저 검역소의 업무를 파악하기 위하여 관 련자료, 연구자료, 사업지침서, 안내서 등을 검토하고, 보 건 사업 및 보건의료기관과 관련된 평가 문헌을 검토하 고 이를 통해 평가틀을 개발하였다[3][4].

$\mathrm{AHP}$ 분석의 적용을 위해 국립검역소 평가는 기관평 과와 서비스/프로그램 평가의 대영역으로 구분되고, 기간 평가는 '투입', '과정', '결과'의 중영역으로 구성되었다. 서비스/프로그램 평가는 '검역', '검사', ‘위생 관련', ‘병 원체조사 감시', ‘전염병 예방 교육 및 홍보'로 분류하였 다. 전체 문항은 15 개로 구성되었고, 기관평가 5 문항, 서 비스 및 프로그램 영역 평가가 10 문항으로 구성되었다.

이러한 분석틀의 설문 문항으로 15 명의 전문가에게 설문조사를 한 결과, 항목 내 평가지표간 중요도 측정시 의사결정자 판단의 논리적 비일관성 비율은 0.078 수준 으로 saaty가 제시한 0.1 보다 작게 나타나[5],[6] 본 연구 의 결과를 신뢰할 수 있음을 보였다. 평가지표별 가중치 는 기관평가 영역이 0.2 , 서비스 및 프로그램 영역이 0.8 로 분석되었으며, 서비스 및 프로그램 영역 내에서 검역 업무가 0.45 로 가장 높게 나타났다. 검역 업무에는 '연간 검역 실적', ‘선박 소독 명령 및 무전 검역 보건위생관리 실적'이 포함되어 있다. 즉, 이를 통해 국립검역소의 사업 내용 중 가장 중요하다고 생각되는 업무는 기관에 대한 평가 보다는 서비스 및 프로그램 영역의 사업 내용이며, 이중에서도 ‘연간 검역 실적'이 가장 중요한 평가를 받고 있음을 알 수 있었다.
학계와 실무자와의 평가지표별 가중치 도출에 대한 차 이를 살펴본 결과 '연간 검역 실적'에 있어서 두 그룹의 점수가 모두 높게 나타났다. 순위 차이가 큰 평가지표는 ‘연간 가검물 검사실적', ‘특성화사업 및 중앙 정부 사업 참여실적', ‘고객(민원)만족도', ‘전염병 예방을 위한 지역 언론 홍보 실적 및 유관기관 및 단체 교육 실적', '정보 공 개‘로 각각의 가중치 평간 점수의 차이는 $0.122,0.038$, $0.047,0.026,0.025$ 로 나타났다. 학계 평가 보다 실무자 평가에서 서비스/프로그램 영역의 항목에 대한 가중치 점수가 높게 도출되어, 실무선에서 중요하게 생각하고 있 는 평가 항목과 학계의 차이가 있음을 알 수 있었다. 그 러나 두 집단 모두 검역 실적이 검역 관리소의 평가에 있 어서 가장 중요한 항목임을 명기하고 있었다.

본 연구에서 적용된 국립검역소사업의 기관평가 세 구 성요소 즉, 투입, 과정 및 결과 간에 어떤 연계가 있는지 를 통합적으로 제시하지는 못하였다. 물론 이들 세 구성 요소의 연관성을 하나의 통합된 평가모형으로 구성해 평 가결과를 산출하는 것은 쉬운 일이 아니지만, 기관평가 모형이 투입, 과정 및 결과 등을 종합적으로 평가하기 위 한 것이라면 추후 평가결과 산출시 이들 구성요소간의 상호연계성을 규명함으로써 평가대상기관을 종합적인 면 에서 평가할 수 있어야 할 것이다.

본 연구에 활용된 15 개의 항목으로 구성된 평가 지표 를 국립검역소의 업무에 적용하여 설문한 결과를 토대로, 향후 국립검역소가 증대해야 할 사업의 방향과 문제점 개선방향을 제시하였다.

15 명의 전문가로 구성된 사업 담당자를 대상으로 한 설문 결과만으로 평가 지표를 완성할 수는 없으나, 국내 국립검역소의 사업 평가를 시도했다는 점에서 연구의 의 의가 있으며, 본 연구를 통해 밝혀진 바에 따라 향후 국 립검역소의 사업 평가는 기관 평가 보다는 서비스 및 프 로그램 평가가 강화되어야 할 것이며, 이 중에서도 특히 '전염병 예방을 위한 지역 언론 홍보 실적 및 유관기관, 단체 교육 실적', ‘정보 공개', ‘특성화 사업 및 중앙정부 사업 참여 실적', '고객(민원) 만족도'와 같이 학계와 실 무자 간의 차이가 큰 평가 항목을 중심으로 한 세부 사업 지침이 마련되어야 할 것이다.

국립검역소사업 평가체계의 구축 및 국제보건규칙에 서 제시한 검역전염병관리 역량 강화에 따른 검역소 업 무의 표준화를 촉진하고 관련지침 개정에 활용될 수 있 을 것이다. 국립검역소사업에 대한 평가 틀 개발 및 검역 소의 특수성을 고려한 평가지표의 개발은 국가 검역전염 병 관리체계 역량강화를 위해 반드시 필요한 것이지만 [3], 현재 개발된 평가 틀 및 평가지표는 완전한 평가지표 가 아니므로, 추후 과학적 근거에 기반한 수정 보완작업 
을 통해 국립검역소 사업의 지속적인 발전을 위한 기초 를 마련해야 할 것이다. 따라서 향후 국제보건 규칙에서 제시한 검역소 역량강화 요건과 해외전염병 국내·외 발 생현황 및 환경에 대한 적절한 평가 틀의 개발과 지표의 수정보완이 지속되어야 할 것이다.

\section{5. 결론}

본 연구는 평가 구성요소 사이의 상대적 중요도, 즉 가 중치(weight) 부여에 있어서 과학적 타당성을 인정받고 있는 계층분석절차(Analytical Hierarchy Process; AHP) 기법에 의한 이원비교방법을 사용하여 설정하였다. 평가 지표별 가중치 결과는 기관평가 영역이 0.2 , 서비스 및 프로그램 영역이 0.8 로 분석되었으며, 서비스 및 프로그 램 영역 내에서 검역 업무가 0.45 로 가장 높게 나타났다. 검역 업무에는 ‘연간 검역 실적', ‘선박 소독 명령 및 무 전 검역 보건위생관리 실적’이 포함되어 있다. 즉, 이를 통해 국립검역소의 사업 내용 중 가장 중요하다고 생각 되는 업무는 기관에 대한 평가 보다는 서비스 및 프로그 램 영역의 사업 내용이며, 이중에서도 '연간 검역 실적' 이 가장 중요한 평가를 받고 있음을 알 수 있었다. AHP 기법은 복잡한 다기준 의사결정문제(multi-criteria decision making problem)를 계층화하여 단순화·체계화 시킴으로써 그 영향도를 계량화하는데 탁월한 기법이라 는 평가를 받고 있다. 실제 측정에 있어서는 본 모형을 이용하여 얻어졌다. 대영역(기관평가영역, 서비스 및 프 로그램평가 영역), 중영역(투입, 과정, 결과, 검역업무, 검 사업무, 위생관리업무, 병원체조사감시업무, 전염병예방 홍보·교육업무)으로 구분하여 최종적으로 평가지표로 선정된 지표는 실제 국립검역소 사업에 적용하였으며, 이 에 대한 최소한의 평가지표를 최종 선정하여 향후 국립 검역소사업 평가체계를 보다 체계화 하였다.

\section{참고문헌}

[1] 신봉춘. 우리나라 검역제도 개선방안에 관한 연구. 부 산대학교. 2001.

[2] 조근태, 홍순옥, 권철신. 리더를 위한 의사결정. 서울, 동현출판사. 2002.

[3] 이무식 등. 광역·자치단체별 전염병 관리사업 평가지 표 확대개발 및 적용. 질병관리본부, 건양대학교. 2006. 12.

[4] 이무식 등. 국립검역소 평가지표 개발. 질병관리본부,
건양대학교 의과대학. 2007. 12.

[5] Saaty, T. A Scaling Method for Priorities in Hierarchical Structures. Journal of Mathematical Psychology, 15, 3, 234 281. 1977.

[6] Saaty T and Bennett JP. A Theory of Analytic Hierarchies Applied to Political Candidacy. Behavioral Science, 22, 237 245. 1977.

정 문 용(Mun-Yong Jeong)

[정회원]

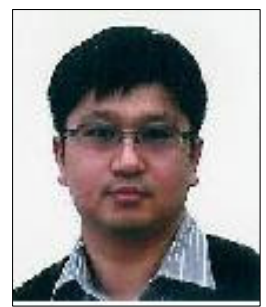

- 2004년 2월 : 건양대학교 의학과

- 2004년 4월 2007년 4월 : 서 구보건소 기성보건지소

- 2007년 3월 2009년 2월 : 건 양대학교 보건복지대학원 보건 학 석사

<관심분야>

보건정책, 건강증진, 병원기획

\section{이 무 식(Moo-Sik Lee)}

[정회원]

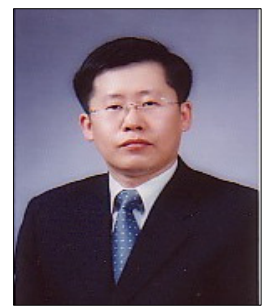

- 1992년 3월 1994년 2월 : 계 명대학교 의과대학 의학석사

- 1994년 3월 1999년 2월 : 계 명대학교 의과대학 의학박사

- 1995년 3월 1998년 4월 : 육 군본부 의무감실군의관(육군대위)

- 1999년 3월 현재 : 건양대학 교 의과대학 부교수

- 2008년 10월 현재 : 건양대학교 임상시험센터 소장

- 2009년 3월 현재 : 건양대학교 보건복지대학원 부원 장

<관심분야>

예방의학, 보건의료정책, 산업의학, 노인의학 
김 대 경(Dae-Kyung Kim)

[정회원]

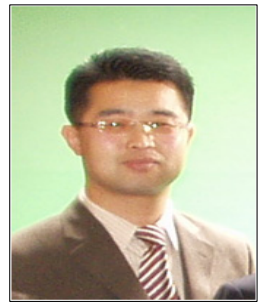

- 1999년 3월 2001년 2월 : 원 광대학교 보건학석사

- 2002년 3월 2006년 2월 : 건 양대학교 예방의학박사

- 2006년 3월 2009년 3월 : 한 국스포츠 산업개발원 원장.

- 2007년 9월 현재 : 목원대학 교 스포츠 산업과학부 교수

<관심분야>

예방의학, 운동처방, 보건의료정책,

유 인 숙(In-Sook Yoo]

[정회원]

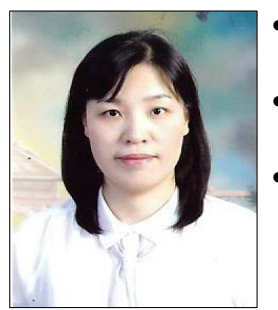

- 1998년 9월 2001년 2월 : 한 양대학교 행정학석사

- 2009년 3월 현재 : 건양대학 교 일반대학원 보건학 박사과정

- 2009년 3월 현재 : 혜천대학

의료정보과 교수

<관심분야>

보건정책, 건강증진, 병원기획 